\title{
Effects of grassland management on the community structure, aboveground biomass and stability of a temperate steppe in Inner Mongolia, China
}

\author{
ZHANG Jinghui, HUANG Yongmei*, CHEN Huiying, GONG Jirui, QI Yu, YANG Fei, \\ LI Engui
}

College of Resources Science and Technology, Beijing Normal University, Beijing 100875, China

\begin{abstract}
Plant community structure responds strongly to anthropogenic disturbances, which greatly influence community stability. The changes in community structure, aboveground biomass (AGB), biodiversity and community stability associated with different management practices were studied with a three-year field investigation in a temperate steppe of Inner Mongolia, China. The species richness, Shannon-Wiener index, evenness, plant functional type abundance, AGB, temporal community stability, summed covariance, scaling coefficient and dominant species stability were compared among areas subjected to long-term reservation (R), long-term grazing (G), mowing since enclosure in 2008 (M) and grazing enclosure since 2008 (E). Site R had higher perennial grass abundance and lower species richness than sites $G, M$ and $E$, although the AGB was not significantly different among the four sites. The species structure varied from a single dominant species at site $R$ to multiple dominant species at sites $G, M$ and $E$. The long-term reservation grassland had lower biodiversity but higher stability, whereas the enclosed grassland with/without mowing had higher biodiversity but lower stability. Different stability mechanisms, such as the compensatory dynamics, mean-variance scaling and dominant species stability were examined. Results showed that community stability was most closely related to the relative stability of the dominant species, which supports the biomass ratio hypothesis proposed by Grime.
\end{abstract}

Keywords: dominant species; biodiversity indices; mass ratio hypothesis; variance-mean scaling; compensatory dynamics

Citation: ZHANG Jinghui, HUANG Yongmei, CHEN Huiying, GONG Jirui, QI Yu, YANG Fei, LI Engui. 2016. Effects of grassland management on the community structure, aboveground biomass and stability of a temperate steppe in Inner Mongolia, China. Journal of Arid Land, 8(3): 422-433. doi: 10.1007/s40333-016-0002-2

Anthropogenic disturbance is steadily altering the ecosystems that human rely on into depauperate ones (Loreau et al., 2001). As a result, the major biogeochemical cycle is changing in unprecedented ways, which may strongly alter composition of ecological communities and reduce the capacity of ecosystem to provide stable function and service (McCann, 2000; Kremen, 2005; Grman et al., 2010). Thus, it is an urgent task for ecologists to understand the changes in community structure and ecosystem function in areas under different management practices. How different management practices affect community structure, and how community structure (e.g. species diversity) influences ecosystem stability have attracted considerable interest of scientists (Garnier et al., 2004; Grman et al., 2010; Zhao et al., 2015).

\footnotetext{
*Corresponding author: HUANG Yongmei (E-mail: ymhuang@bnu.edu.cn)

Received 2015-06-30; revised 2015-10-28; accepted 2015-11-03

(C) Xinjiang Institute of Ecology and Geography, Chinese Academy of Sciences, Science Press and Springer-Verlag Berlin Heidelberg 2016
} 
Grassland is the primary vegetation type throughout the world, most of which has been explored to grazing or mowing practice (White et al., 2000; Conant et al., 2001). Grazing can influence grassland community structure directly through defoliation, trampling, dung and urine depositions, indirectly through changes of species interactions and abiotic environment (Hodgson and Illius, 1996). The changes in abundance of grazing tolerance species and grazing avoidance species will definitely influence ecosystem function (e.g. productivity and stability). Mowing is another important management practice in grassland and is a major driver of community structure and function. The removal of tall, tussock-forming species can reduce litter accumulation and improve canopy radiation, which will have benefit on the growth and recruitment of small plants (Collins et al., 1998). Yang et al. (2012) also suggested that mowing could significantly alter community stability, besides results have indicated mowing and grazing could alter species richness (Wahlman and Milberg, 2002; Diaz et al., 2007; Yang et al., 2011).

The relationship between biodiversity and community stability has long been a subject of interest (Doak et al., 1998; Tilman et al., 1998). Recently, numerous studies used statistical or model approaches to uncover the mechanisms driving community stability, instead of simply focused on the relationship between biodiversity and community stability (Doak et al., 1998; Lehman and Tilman, 2000; Loreau and de Mazancourt, 2013). Competition model and mechanistic models of stochastic community dynamics in fluctuating environments highlighted stability mechanisms such as competition and the asynchrony of species' responses to environmental fluctuations (Ives et al., 1999; Lehman and Tilman, 2000; Loreau and de Mazancourt, 2013), while empirical studies had focused on testing the mechanisms such as compensatory dynamics, mean-variance scaling relationship and dominant species stability. These mechanisms were easily applied to empirical data and had been testified effective in grassland ecosystem (Bai et al., 2004; Polley et al., 2007).

Increasing the abundance of one species would result in compensatory decreases in other species due to niche overlap in resources or space, the phenomenon called the compensatory dynamics (Ranta et al., 2008). This negative response can reduce variation in total abundance at the community level and improve community stability (Grman et al., 2010). When the summed species covariance is negative, compensatory dynamics plays a dominant role in the community stability (Ives, 1995; Ranta et al., 2008). Another hypothesis is the mean-variance scaling relationship (Taylor, 1961), described as $\sigma^{2}=c \mu^{z}$, where $\sigma^{2}$ is the variance of species abundance, and $u$ is mean species abundance (Cottingham et al., 2001). Species characterized by higher values of $z$ will be more variable than species with a lower $z$ if they have equally abundance (Cottingham et al., 2001; Grman et al., 2010). When $z>1$ and each species has an equivalent role, the total community temporal stability increases as diversity increases (Tilman, 1999; Cottingham et al., 2001). However, in natural communities, summed covariances were more often positive than negative (Valone and Barber, 2008), higher variability populations (higher $z$ ) will increase summed variance, thus lead to lower community stability (Petchey et al., 2002; Romanuk et al., 2006). And it has been suggested that community stability depend at least as much on stability of dominant species as on biodiversity (Polley et al., 2007; Sasaki and Lauenroth, 2011), which is consistent with Grime's mass ratio hypothesis (Grime, 1998). This hypothesis predicted that ecosystem function, including stability, is largely controlled in a short term by the traits of dominant species (Grime, 1998).

The temperate steppe in Inner Mongolia, as a large part of the Eurasian steppe (Yang et al., 2012), has been subjected to grazing and mowing with a long history since the beginning of humanity (Bai et al., 2012), now grassland exclusion to avoid grazing and mowing becomes a widely used sustainable management practice. The effects of these management practices on community structure and productivity have been reported widely (Wan et al., 2009; Yang et al., 2012), however little is known about the effect of them on community stability and the mechanisms underline stability. Here, we surveyed the temperate steppe structure, aboveground biomass $(\mathrm{ABG})$ and temporal stability responses to different management practices (e.g. grazing, mowing and enclosure) in Inner Mongolia, China. We also testified the community stability mechanisms in Inner Mongolian steppe, including compensatory dynamics, mean-variance 
scaling and stability of dominant species (Grman et al., 2010). We conducted a three-year field survey to test the following hypotheses: (1) grassland management practices could shape community structure (Hooper et al., 2005; Grman et al., 2010), and (2) community stability should be controlled by the stability of dominant species (Grime, 1998; Polley et al., 2007) in a temperate steppe.

\section{Materials and methods}

\subsection{Site selection and sampling}

The field survey was conducted in Maodeng pasture $\left(44^{\circ} 10^{\prime} \mathrm{N}, 116^{\circ} 22^{\prime} \mathrm{E}\right)$, with a gentle slope $\left(<3^{\circ}\right)$, in Inner Mongolia, China. The annual average temperature was $2.36^{\circ} \mathrm{C}$ and the annual precipitation was $281 \mathrm{~mm}$ (average during 1953-2013). The annual precipitation was 226.7, 511.7 and $273.4 \mathrm{~mm}$ in 2011, 2012 and 2013, respectively. The evaporation is about 5.8 times that of precipitation. The soil at the study area is called chestnut soil (Bai et al., 2008), according to the Chinese Soil Taxonomy System; this is similar to Haplic Kastanozem in the FAO system. This grassland, which is part of the Eurasia Steppe, is dominated by Stipa grandis, Leymus chinensis and Cleistogenes squarrosa.

Four areas were selected with different management practices: the long-term grazing area $(\mathrm{G})$, having been grazed since 1956, with cow stocking capacity of $0.27 \mathrm{hm}^{2}$ (survey data from herdsman); the mowed area (M), about $2.73 \times 10^{4} \mathrm{hm}^{2}$ large and having been practiced with grass-mowing (with a height of $180 \mathrm{~cm}$ ) in August once a year since grazing was excluded in 2008; the grazing enclosed area (E), about $500 \mathrm{hm}^{2}$ large and having been stopped grazing and mowing since 2008; and the long-term reservation area $(\mathrm{R})$ where was free from grazing since 1956. Site R was within an ecologically protected area and was away from residential areas with the lowest human disturbance. The long-term grazing, mowed and enclosed areas had been with the same grazing stocking before 2008 .

As the grazing exclusion project was a natural experiment conducted at the landscape level, we set up three plots $(100 \mathrm{~m} \times 100 \mathrm{~m})$ randomly within each management area; the minimum distance between plots was $500 \mathrm{~m}$ (Fischer et al., 2010; Socher et al., 2013). Three permanent sub-plots $(10 \mathrm{~m} \times 10 \mathrm{~m})$ were randomly set up within each replicated plot. The living aboveground biomass (AGB) was clipped and sorted by species from a quadrat $(1 \mathrm{~m} \times 1 \mathrm{~m})$ randomly assigned within each sub-plot in August 2011, 2012 and 2013, when the biomass had reached its annual peak (Bai et al., 2004). All samples were oven-dried at $65^{\circ} \mathrm{C}$ for $48 \mathrm{~h}$ and weighed, then the aboveground biomass ( $\mathrm{g}$ dry matter $/ \mathrm{m}^{2}$ ) of each functional type (i.e. perennial grasses $(\mathrm{PG})$, perennial forbs (PF) and annuals (AS); Bai et al., 2008) and community were calculated.

\subsection{Biodiversity indices and temporal stability}

We calculated biodiversity indices based on the quadrat data. Richness $(S)$ was the number of species present in each quadrat. The Shannon-Wiener index was calculated as:

$$
H^{\prime}=-\sum_{i=l}^{S} p_{i} \ln p_{i} .
$$

Where $p_{i}$ is the proportion of the AGB contributed by species $i$ to the community AGB (Magurran, 1988). Evenness was calculated as $H^{\prime} / \ln S$.

Temporal stability was calculated using the three-year community AGB, which can be expressed as (Tilman, 1999):

$$
\begin{gathered}
S_{T}=\frac{\mu_{T}}{\sigma_{T}}, \quad(2) ; \quad \mu_{T}=\left(\sum_{2011}^{2013} x_{C}\right) / 3, \\
\sigma_{T}=\sqrt{\operatorname{Var}\left(X_{C}\right)}=\sqrt{\left[\left(\left(X_{C}\right)_{2011}-\mu_{T}\right)^{2}+\left(\left(X_{C}\right)_{2012}-\mu_{T}\right)^{2}+\left(\left(X_{C}\right)_{2013}-\mu_{T}\right)^{2}\right] / 3} .
\end{gathered}
$$

Where $S_{T}$ is the community temporal stability, $\mu_{T}$ is the mean community AGB $\left(\mathrm{g} / \mathrm{m}^{2}\right)$ from 2011 to $2013, X_{C}$ is the AGB of each quadrat $(\mathrm{g} / \mathrm{m}), \sigma_{T}$ is the standard deviation of community AGB and $\operatorname{Var}\left(X_{C}\right)$ is the variance in each quadrat. 


\subsection{Compensatory dynamics test}

The summed covariance between species pairs was calculated using the variance in community biomass and the sum of the variances of individual species (Box et al., 1978; Polley et al., 2007) as follows:

$$
\begin{gathered}
\operatorname{Var}\left(X_{C}\right)=\operatorname{Var}\left(\sum_{i=1}^{S} x_{i}\right)=\sum_{i}^{S} \operatorname{Var}\left(x_{i}\right)+2 \sum_{i \neq k}^{S} \operatorname{Cov}\left(x_{i}, x_{k}\right), \\
\sum_{i \neq k}^{S} \operatorname{Cov}\left(x_{i}, x_{k}\right)=\left[\operatorname{Var}\left(\sum_{i=1}^{S} x_{i}\right)-\sum_{i}^{S} \operatorname{Var}\left(x_{i}\right)\right] / 2 .
\end{gathered}
$$

Here,

$$
\begin{gathered}
\operatorname{Var}\left(x_{i}\right)=\left[\left(\left(x_{i}\right)_{2011}-\mu_{i}\right)^{2}+\left(\left(x_{i}\right)_{2012}-\mu_{i}\right)^{2}+\left(\left(x_{i}\right)_{2013}-\mu_{i}\right)^{2}\right] / 3, \\
\mu_{i}=\left(\sum_{i=2011}^{2013} x_{i}\right) / 3 .
\end{gathered}
$$

Where $S$ is species richness in each quadrat, $x_{i}$ is AGB of species $i$ in each quadrat $\left(\mathrm{g} / \mathrm{m}^{2}\right)$, and $\operatorname{Var}\left(x_{i}\right)$ is the variance of species $i$ in each quadrat. $\operatorname{Cov}\left(x_{i}, x_{k}\right)$ is covariance of species $i$ and $k$, and $\mu_{i}$ is average AGB of species $i$ during the period 2011-2013. The sum of the covariances is zero when species vary independently. If compensatory dynamics dominate, the sum of the covariances is negative (Ranta et al., 2008).

\subsection{Scaling coefficient and dominant species stability}

The scaling coefficient, $z$, was derived from Taylor's power law (Taylor, 1961), $\sigma^{2}=c \mu^{z}$, where $c$ is a constant, $\sigma^{2}$ is the variance in species biomass, and $\mu$ is the mean species biomass. After logarithmic conversion, the equation can be expressed as (Polley et al., 2007):

$$
\log \left[\operatorname{Var}\left(x_{i}\right)\right]=c+z \times \log \left(\mu_{i}\right) .
$$

We fit a linear regression to the relationship between the logarithm of temporal variance and the logarithm of temporal mean biomass for each species and used the slope of this regression to obtain the $z$ value. An analysis of covariance (ANCOVA) was used to test the scaling coefficient with different management types as covariates. Significant interactions between management types and $\log (\mu)$ indicated that the different management types had an effect on the mean-variance scaling relationship (Grman et al., 2010).

We selected the most dominant species ( $n=3-5$; relative biomass $>5 \%$ ), including $S$. grandis, $C$. squarrosa, L. chinensis, Artemisia frigida and Chenopodium album for analysis. Among the five species, $S$. grandis and L. chinensis are the most important perennial $\mathrm{C}_{3}$ grasses, C. squarrosa is a major perennial $\mathrm{C}_{4}$ grass in the Inner Mongolian grassland (Auerswald et al., 2012), A. frigida is a perennial forb and $C$. album is an annual. The logarithm of the variance and logarithm of the mean AGB for each species within each sub-plot were subjected to variance-mean fitting, and the linear regression fit was used to calculate the expected coefficient of variation $(C V)$. The observed $C V$ of species $i$ was calculated as:

$$
C V_{i}=\frac{\sqrt{\operatorname{Var}\left(x_{i}\right)}}{\mu_{i}} .
$$

We compared the observed $C V$ and the expected $C V$ of biomass for the most dominant species ( $n=3-5)$. A larger observed $C V$ than expected $C V$ indicates that the species is less stable than that of other species in the community (Polley et al., 2007).

\subsection{Statistical analysis}

All dependent variables of the three sub-plots per plot were averaged, and the AGB was logarithmically converted before analysis. Statistical analyses were performed using SPSS 19.0 (SPSS Inc., Chicago, IL, USA). Management effects on functional groups, temporal stability and sum of covariance were tested by an analysis of variance (ANOVA). The effect on biodiversity and AGB was tested by a repeated-measure ANOVA (RMANOVA), with year as the within-subjects factor and management type as the between-subjects factor. One-sample $t$-tests 
were used to examine if the average sum of covariance differed significantly from zero. Independent-sample $t$-tests were used to examine whether the observed species $C V$ was significantly different from the expected $C V$.

\section{Results}

\subsection{Biodiversity and functional type abundance}

The species richness was lower at site $\mathrm{R}$ than those at the other three sites $(F=8.223, P=0.002$; Table 1), whereas approximately the same species richness was found at sites $\mathrm{G}, \mathrm{M}$ and $\mathrm{E}$ $(F=0.13, P=0.879$; Table 1). The lowest Shannon-Wiener index $(F=18.725, P<0.001)$ and evenness $(F=6.866, P=0.001)$ values occurred at site $\mathrm{R}$ and were similar among the other three sites $(F=2.638, P=0.116$ and $F=2.502, P=0.127$; Table 1$)$.

Table 1 Biodiversity indices based on management practices

\begin{tabular}{|c|c|c|c|}
\hline Site & $\begin{array}{c}\text { Shannon-Wiener } \\
\text { index }\end{array}$ & Richness & Evenness \\
\hline Long-term reservation $(\mathrm{R})$ & $1.06 \pm 0.08^{b}$ & $8.42 \pm 0.42^{b}$ & $0.50 \pm 0.03^{b}$ \\
\hline Long-term grazing $(\mathrm{G})$ & $1.47 \pm 0.02^{\mathrm{a}}$ & $11.00 \pm 0.41^{\mathrm{a}}$ & $0.62 \pm 0.02^{\mathrm{a}}$ \\
\hline Mowed (M) & $1.57 \pm 0.05^{\mathrm{a}}$ & $11.07 \pm 0.68^{\mathrm{a}}$ & $0.67 \pm 0.02^{\mathrm{a}}$ \\
\hline Enclosed (E) & $1.60 \pm 0.05^{\mathrm{a}}$ & $11.33 \pm 0.24^{\mathrm{a}}$ & $0.67 \pm 0.03^{\mathrm{a}}$ \\
\hline
\end{tabular}

Note: Data (values are means \pm SE) marked with different letters are significantly different $(P<0.05$, repeated-measure ANOVA).

Almost no shifts in the abundance (percentage of the AGB) of functional types were observed at site R during the period 2011-2013. The proportions of the AGB from PG were $88.3 \%, 87.8 \%$ and $89.2 \%$, respectively. The second most abundant type was PF, whereas AS accounted for only $0.03 \%, 0.62 \%$, and $0.04 \%$, respectively (Fig. 1). Site G was dominated by PG with $88.6 \%$ in 2011 , $63.1 \%$ in 2012 and $93.4 \%$ in 2013 . The plant functional type abundance fluctuated widely by year at sites $\mathrm{M}$ and $\mathrm{E}$ compared with that at site R. The contribution of $\mathrm{PG}$ was $67.3 \%$ and $63.5 \%$ at sites $\mathrm{M}$ and $\mathrm{E}$, respectively, in 2011 (Fig. 1a) in comparison to $54.0 \%$ and $34.7 \%$ in 2012 (Fig. 1b) and $80.0 \%$ and $87.2 \%$ in 2013 (Fig. 1c). The abundance of AS increased in 2012 at sites G, M and E (accounting for $22.6 \%, 27.6 \%$ and $31.8 \%$, respectively) compared with those in 2011 and 2013 (Fig. 1).

\subsection{Community aboveground biomass and temporal stability}

Aboveground biomass (AGB) did not differ consistently among different management practices inter-annually $\left(125.42,132.49,137.67\right.$ and $136.53 \mathrm{~g} / \mathrm{m}^{2}$ for sites of $\mathrm{R}, \mathrm{G}, \mathrm{M}$ and $\mathrm{E}$, respectively. $F=0.347 ; P=0.792$ for the interaction between year and management in a repeated measures ANOVA (RMANOVA); Fig. 2a).

Community temporal stability was higher at site $\mathrm{R}$ than those at site $\mathrm{M}(P=0.008)$ and site $\mathrm{E}$ $(P=0.007$; Fig. 2b), whereas no difference was found between sites $\mathrm{R}$ and $\mathrm{G}(P=0.231)$. The community temporal stability at site $\mathrm{G}$ was $44 \%$ higher than that at site $\mathrm{M}(P=0.061)$ and was $48 \%$ higher than that at site $\mathrm{E}(P=0.053$; Fig. $2 \mathrm{~b})$.

\subsection{Summed species covariance, scaling coefficient and dominant species stability}

The summed species covariance was negative at site $\mathrm{R}$ but positive at sites $\mathrm{G}, \mathrm{M}$ and $\mathrm{E}$; none of the values were significantly different from zero $(P=0.202, t=-1.870 ; P=0.180, t=2.029 ; P=0.119$, $t=2.636$; and $P=0.836, t=0.226$, respectively). The summed species covariance was not significantly different among the four sites $(F=2.178, P=0.136)$, indicating that the species at the four sites varied independently and there was no significant interspecific interaction (Fig. 2c). 

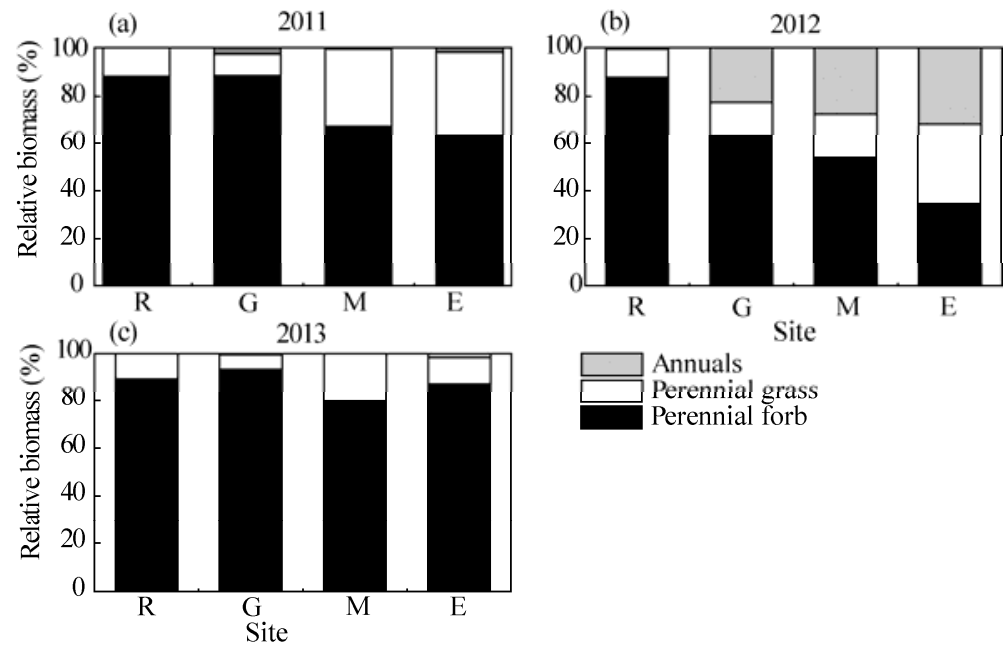

Fig. 1 Effect of management practices on the abundance of plant functional types (percentage aboveground biomass (AGB)) in 2011 (a), 2012 (b) and 2013 (c). R, long-term reservation site; G, long-term grazing site; M, mowed site; $\mathrm{E}$, enclosed site.
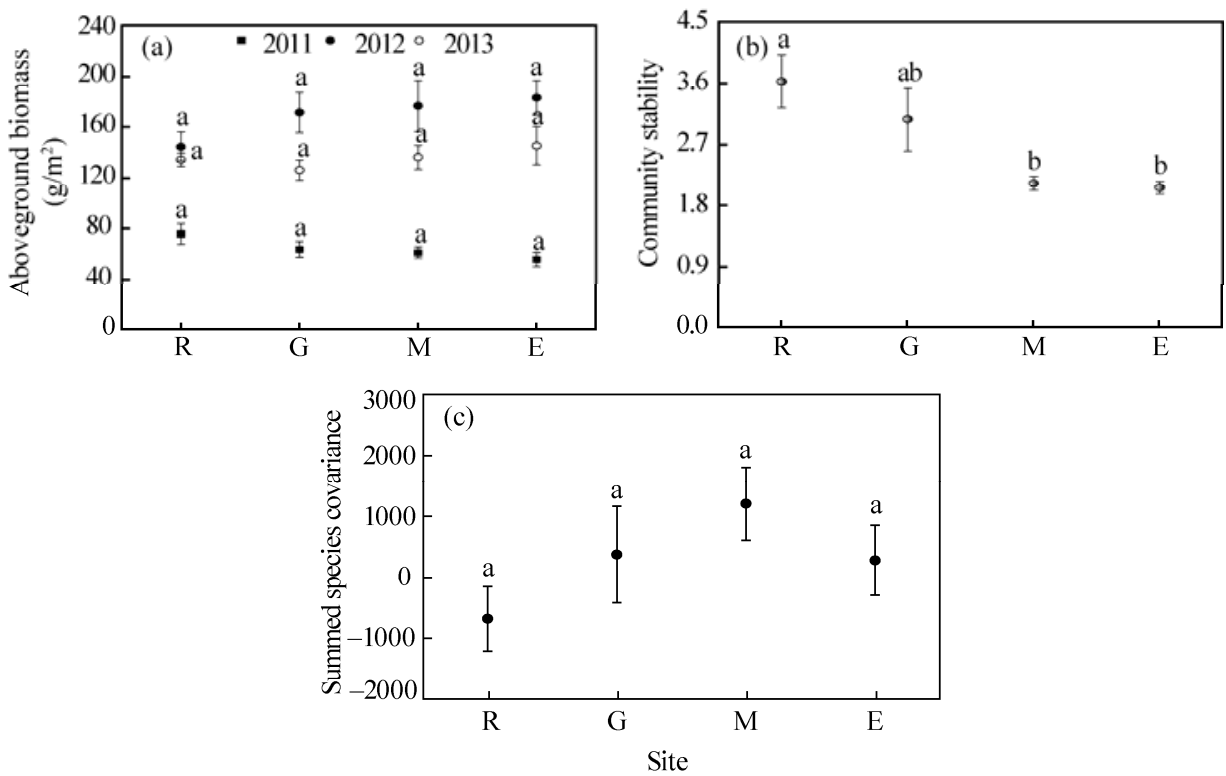

Fig. 2 Aboveground biomass during 2011-2013 (a), community temporal stability (b) and summed species covariance (c) at the four sites. Error bars indicate standard errors. Data marked with different letters are significantly different among four sites for the same year $(P<0.05)$. R, long-term reservation site; $\mathrm{G}$, long-term grazing site; M, mowed site; E, enclosed site.

The scaling coefficient, $z$, was quite different at the four sites (Fig. 3). The $z$ value was 1.66 at site $\mathrm{R}$, which is significantly smaller than that at site $\mathrm{G}(z=1.75$, ANCOVA $\ln (\mu) \times$ management $\left.F_{1,229}=10.589, P<0.001\right)$, site $\mathrm{M}\left(z=1.77\right.$, ANCOVA $\ln (\mu) \times$ management $\left.F_{1,231}=14.642, P<0.001\right)$, and site $\mathrm{E}\left(z=1.83\right.$, ANCOVA $\ln (\mu) \times$ management $F_{1,227}=20.107, P<0.001$; Fig. 3$)$.

The four sites shared a similar species pool, as most species appeared in all plots. However, the species AGB contributions to the community differed among the four sites (Table 2). S. grandis was the single dominant species at site R (67\% of the AGB). Leymus chinensis was the most abundant species at site G; it contributed $45 \%$ of the AGB. The dominant species at site $\mathrm{M}$ were $L$. chinensis, $C$. squarrosa and $A$. frigida, with relative AGB values of $20 \%, 17 \%$ and $17 \%$, respectively. The dominant species at site E were L. chinensis, A. frigida and S. grandis, with relative AGB values of $22 \%, 17 \%$ and $17 \%$, respectively. 

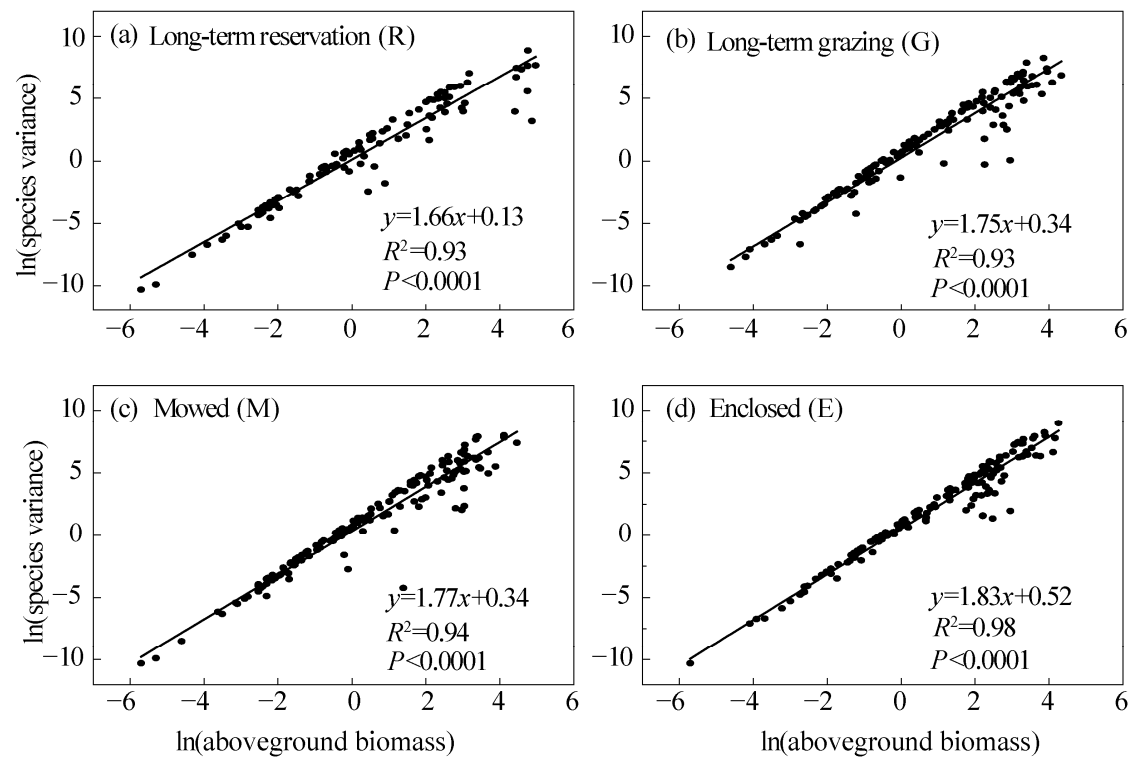

Fig. 3 Relationships between the logarithm of species variance and the logarithm of mean species abundance at the four sites. The slope of the fitted curve was the scaling coefficient, $z$.

The observed $C V$ values for the three most dominant species did not differ significantly from the expected $C V$ at sites $\mathrm{R}$ and $\mathrm{G}$ (Table 2). The relative AGB of $C$. squarrosa at site $\mathrm{M}$ was $17 \%$, and the observed $C V$ was significantly larger than the expected $C V(P=0.036, n=18)$, indicating that this species was less stable than the other species in the community. $C$. squarrosa and $C$. album were rather abundant at site $\mathrm{E}$, with relative AGB values of $14 \%$ and $8 \%$, respectively, but the observed $C V s$ of both the species were larger than the expected values $(P=0.016, n=18$ and $P<0.001, n=18$, respectively; Table 2).

Table 2 Mean relative aboveground biomass (AGB) of dominant species with different management practices during the period of 2011-2013

\begin{tabular}{|c|c|c|c|c|c|}
\hline Management type & Species & $\begin{array}{c}\text { Percentage of } \\
\text { AGB }(\%)\end{array}$ & $\begin{array}{c}\text { Observed } \\
\text { CV }\end{array}$ & $\begin{array}{c}\text { Expected } \\
C V\end{array}$ & $P$ value \\
\hline \multirow[t]{3}{*}{ Long-term reservation } & Stipa grandis & 67.0 & 0.31 & 0.43 & 0.161 \\
\hline & Leymus chinensis & 9.0 & 0.77 & 0.68 & 0.662 \\
\hline & Cleistogenes squarrosa & 13.0 & 0.55 & 0.60 & 0.846 \\
\hline \multirow[t]{3}{*}{ Long-term grazing } & Stipa grandis & 11.0 & 0.65 & 0.77 & 0.591 \\
\hline & Leymus chinensis & 45.0 & 0.40 & 0.60 & 0.249 \\
\hline & Cleistogenes squarrosa & 18.0 & 0.68 & 0.70 & 0.883 \\
\hline \multirow[t]{4}{*}{ Mowing } & Stipa grandis & 8.0 & 1.12 & 1.02 & 0.663 \\
\hline & Leymus chinensis & 20.0 & 0.68 & 0.93 & 0.064 \\
\hline & Cleistogenes squarrosa & 17.0 & 1.05 & 0.80 & 0.036 \\
\hline & Artemisia frigida & 17.0 & 0.84 & 0.93 & 0.702 \\
\hline \multirow[t]{5}{*}{ Enclosure } & Stipa grandis & 17.0 & 0.92 & 1.10 & 0.277 \\
\hline & Leymus chinensis & 22.0 & 0.76 & 1.03 & 0.132 \\
\hline & Cleistogenes squarrosa & 14.0 & 1.05 & 0.75 & 0.016 \\
\hline & Artemisia frigida & 17.0 & 1.10 & 1.06 & 0.749 \\
\hline & Chenopodium album & 8.0 & 1.68 & 1.11 & 0.000 \\
\hline
\end{tabular}

Note: The observed coefficient of variation $(\mathrm{CV})$ was the ratio of the variance of relative AGB to mean relative AGB. The expected $C V$ was calculated using the variance-mean relationship for each plot. Independent-sample $t$-tests were used to test whether the observed $C V$ differed significantly from the expected $C V$ for each dominant species $(P<0.05$ was significant, marked in bold). 


\section{Discussion}

\subsection{Community structure response to grassland management practices}

No differences in AGB were found among the four management practices, although the history, intensity and frequency of human interference differed (Fig. 2a). Two reasons may account for this result, firstly, the ecosystem can resist disturbances and restructure when faced with certain change to maintain a certain level of stable productivity (Folke et al., 2004; Walker et al., 2004). Secondly, many researchers suggested that whether grassland productivity increase or decrease depends on stocking density (Karsten and Fick, 1999), the relative low level of stocking densities in our study may partly explain the result. But the management strategies markedly affect the biodiversity and structural characteristics of communities in our study. From perspective of biodiversity, historically grazing and mowing in sites G, M and E tend to increase and maintain species richness and evenness (Table 1), which confirms with the findings in other grassland (Wahlman and Milberg, 2002) and the results reported in a meta-analysis (Hillebrand et al., 2007). Structurally, shift of dominant species among four sites has been observed. S. grandis was the only dominant species at site $\mathrm{R}$, whereas the single dominant species at site $\mathrm{G}$ was L. chinensis. Sites $\mathrm{M}$ and $\mathrm{E}$ had four to five dominant species, respectively, and the abundance of the perennial forb A. frigid increased significantly (Table 2). Besides, there was also a shift of functional group. For instance, site $\mathrm{R}$ had a greater abundance of PG (Fig. 1), the abundance of AS clearly increased at sites G, M and E during the wet years compared with that at site R (Fig. 1), but no significant difference was observed among the other three sites. A mechanism may account for these effects on biodiversity and community structure: livestock defoliation and trampling as well as mowing can reduce the coverage of tall species (e.g. S. grandis), which will improve canopy radiation and increase the abundance of other species (Collins et al., 1998). Thus, we draw the conclusion that a long-term minimal disturbance would result in a mono-dominant community in the Inner Mongolian grassland, and that grazing or mowing would result in multiple dominant species in the grassland.

\subsection{Impact of management on grassland stability and investigation of mechanisms driving stability}

The composition of the functional groups at site $\mathrm{R}$ did not change, although the annual precipitation differed during the three years (Fig. 1). The descending order of community stability was sites R, G, M and E (Fig. 2b), whereas the descending disturbance level was sites G, M, E and $\mathrm{R}$. It is interesting that sites $\mathrm{M}$ and $\mathrm{E}$ experience less disturbance than the grazed plots, why then do they have lower stability? To answer this question, we investigated three hypotheses that could determine community stability, including compensatory dynamics, mean-variance scaling and stability of the dominant species (Grman et al., 2010).

Many ecologists believe that greater community diversity leads to greater stability (Tilman and Downing, 1994; Loreau et al., 2001). However, we found that the long-term reservation site had lower species richness but higher stability, whereas the mowed and enclosed sites had higher biodiversity but lower stability. It seems that community stability was negatively related to species diversity in the grassland. This result was different but not the only one. For example, Ives and Carpenter (2007) found that $69 \%$ relationships were positive and $14 \%$ relationships were negative in the 59 biodiversity-stability relations. The biodiversity-stability hypothesis suggests that communities with higher biodiversity may increase the probability of containing species negative responses to environmental fluctuations (Doak et al., 1998; Tilman et al., 1998), and have greater opportunity to contain specific species that are stable during environmental fluctuations (Tilman and Downing, 1994; Loreau et al., 2001). To explain the relationship between biodiversity and stability in our communities, we needed to clarify whether the species' responses to environmental fluctuations were negatively correlated and whether a more diverse community had more stable species.

Compensatory dynamics refers to an increase in species abundance coincident with a decrease in the abundance of another species. Asynchrony of species responses to environmental fluctuations can lead to negative interactions between species (Bai et al., 2004; Loreau and de Mazancourt, 2013), reducing community covariance and increasing stability (Bai et al., 2004; 
Ranta et al., 2008). When the summed species covariance is negative, compensatory dynamics play a dominant role in the community (Ranta et al., 2008). In this study, we found that the sum of the covariance values were all not significantly different from zero (Fig. 2c), indicating that compensatory dynamics were not working on these grasslands. This may because the coexisting species shared common resource base and affected by their environment in similar ways thus did not response to environmental fluctuations negatively (Loreau and de Mazancourt, 2008). Our result suggested that high diversity had no effect on decreasing the summed covariance and stabilizing the community, which may partly explain the negative relationship between stability and biodiversity in these communities,

A large scaling coefficient $(z)$ indicates that the change in variance is much greater than that of the mean species AGB, and that the species in the community are more variable (Grman et al., 2010). The long-term reservation site had a lower $z$ value, whereas the mowed and enclosed sites had higher $z$ values, indicating that the species at sites $\mathrm{M}$ and $\mathrm{E}$ were more variable (Grman et al., 2010). Many studies have showed that when $z>1$, positive relationship between richness and community stability occurred (Tilman, 1999; Cottingham et al., 2001). In contrast, we found scaling coefficient in all communities was large than 1, while the richness was negatively with community stability. The community variance includes two parts: the variance of species and the covariance between species. In this study, variable species in high biodiversity sites (sites $\mathrm{M}$ and E) would increase the summed variance, and the summed covariance was not significantly different among management sites; thus variable species will lead to more variable community (Petchey et al., 2002; Romanuk et al., 2006). Mean-variance scaling may have been the mechanism determining community stability in our study; however, its strength is difficult to assess (Polley et al., 2007; Grman et al., 2010). To further analyze why the mowed and enclosed sites had higher $z$ values, we investigated the stability of the most dominant species in the study area.

The types of dominant species largely determine the properties of community, and more variable dominant species will lead to more variable communities (Polley et al., 2007; Grman et al., 2010). In our study, the relative AGB of Cleistogenes squarrosa at site $\mathrm{M}$, and those of $C$. squarrosa and Chenopodium album at site E were higher, but their stability was lower (Table 1). C. album is an annual, meaning it must regenerate annually from seed and is more sensitive to environmental variability (Grman et al., 2010). C. squarrosa is a perennial $\mathrm{C}_{4}$ grass, and its abundance is more sensitive to moisture in the Inner Mongolian grassland (Auerswald et al., 2012). The mowed and enclosed sites would suffer quick changes by following the secondary succession path during the early stages of a management change (since 2008), resulting in lower stability of $C$. squarrosa and C. album. The stability of dominant species thus was an important mechanism which can underlie the changes in community stability among different grassland managements. Our findings are consistent with the result that diversity-stability relationships might be restricted by the properties of dominant species (Lepš, 2004; Polley et al., 2007; Sasaki and Lauenroth, 2011), supporting Grime's (1998) mass ratio hypothesis (Grime, 1998).

Large-scale natural experiments provide an integrative and holistic approach to basic ecology, and when combined with a small well-replicated study, they can offer great insight (Likens, 1985; Carpenter, 1990). However, the results of natural experiments are often not amenable to replication (Millard, 1987; Carpenter, 1989). However, un-replicated large-scale natural experiments can still be used to check an existing theory about a particular system (Cottenie and De Meester, 2003). In this study, we explored how the most common management strategies affect grasslands based on community structure, AGB and stability. As other grasslands differ ecologically and are under different land-use regimes, serendipitous management of the grassland was not replicated; thus, pseudo-replicates were used, and the results had limited scope to demonstrate that human disturbance causes changes in natural ecosystems (Hurlbert, 1984; Stewart-Oaten et al., 1986). Insufficient replication may result in an erroneous and insignificant result, and may be worse than no replication. Thus, a meta-analysis of a number of un-replicated experiments arrayed across major ecological gradients would be powerful (Carpenter, 1989; Cottenie and De Meester, 2003). Our study is a replicate of such a meta-analysis; and additional long-term experiments are needed to test the changes caused by different grassland management practices. 


\section{Conclusions}

The long-term reservation grassland with minimal human disturbance featured a single dominant species, whereas the long-term free-grazing grassland, the mowed grassland and the enclosed grassland (i.e. with more disturbances) featured higher species richness and multiple dominant species in the temperate steppe of Inner Mongolia, China. The long-term reservation grassland had lower biodiversity but higher stability, whereas the mowed and enclosed grasslands had higher biodiversity but lower stability. Such a negative relationship between biodiversity and stability may be due to high variability in the constituent species and a more synchronous response to environmental fluctuations of the species in a community with greater biodiversity. The mowed and enclosed grasslands were in the early stages of a change in management, and the variety and low stability of the dominant species may have been the reason for the low community stability. Additional long-term studies of the effects of changes in management strategy on grassland structure, stability, and related mechanisms are needed.

\section{Acknowledgements}

This study was funded by the National Natural Science Foundation of China $(41030535,41371069)$, the Fundamental Research Funds for the Central Universities and the Program for Changjiang Scholars and Innovative Research Team in University (IRT1108).

\section{References}

Auerswald K, Wittmer M H O M, Bai Y F, et al. 2012. $\mathrm{C}_{4}$ abundance in an Inner Mongolia grassland system is driven by temperature-moisture interaction, not grazing pressure. Basic and Applied Ecology, 13(1): 67-75.

Bai Y F, Han X G, Wu J G, et al. 2004. Ecosystem stability and compensatory effects in the Inner Mongolia grassland. Nature, 431(7005): 181-184.

Bai Y F, Wu J G, Xing Q, et al. 2008. Primary production and rain use efficiency across a precipitation gradient on the Mongolia plateau. Ecology, 89(8): 2140-2153.

Bai Y F, Wu J G, Clark C M, et al. 2012. Grazing alters ecosystem functioning and C:N:P stoichiometry of grasslands along a regional precipitation gradient. Journal of Applied Ecology, 49(6): 1204-1215.

Box G E P, Hunter W G, Hunter J S. 1978. Statistics for Experimenters. Hoboken: John Wiley \& Sons.

Carpenter S R. 1989. Replication and treatment strength in whole-lake experiments. Ecology, 70(2): 453-463.

Carpenter S R. 1990. Large-scale perturbations: opportunities for innovation. Ecology, 71(6): 2038-2043.

Collins S L, Knapp A K, Briggs J M, et al. 1998. Modulation of diversity by grazing and mowing in native tallgrass prairie. Science, 280(5364): 745-747.

Conant R T, Paustian K, Elliott E T. 2001. Grassland management and conversion into grassland: effects on soil carbon. Ecological Applications, 11(2): 343-355.

Cottenie K, De Meester L. 2003. Comment to Oksanen (2001): reconciling Oksanen (2001) and Hurlbert (1984). Oikos, 100(2): 394-396.

Cottingham K L, Brown B L, Lennon J T. 2001. Biodiversity may regulate the temporal variability of ecological systems. Ecology Letters, 4(1): 72-85.

Díaz S, Lavorel S, Mcintyre S et al. 2007. Plant trait responses to grazing-a global synthesis. Global Change Biology, 13(2): 313-341.

Doak D F, Bigger D, Harding E K, et al. 1998. The statistical inevitability of stability-diversity relationships in community ecology. The American Naturalist, 151(3): 264-276.

Fischer M, Bossdorf O, Gockel S, et al. 2010. Implementing large-scale and long-term functional biodiversity research: The biodiversity exploratories. Basic and Applied Ecology, 11: 473-485.

Folke C, Carpenter S R, Walker B, et al. 2004. Regime shifts, resilience and biodiversity in ecosystem management. Annual Review of Ecology, Evolution and Systematics, 35: 557-581.

Garnier E, Cortez J, Billès G, et al. 2004. Plant functional markers capture ecosystem properties during secondary succession. Ecology, 85(9): 2630-2637.

Grime J P. 1998. Benefits of plant diversity to ecosystems: immediate, filter and founder effects. Journal of Ecology, 86(6): 902-910. 
Grman E, Lau J A, Schoolmaster D R Jr, et al. 2010. Mechanisms contributing to stability in ecosystem function depend on the environmental context. Ecology Letters, 13(11): 1400-1410.

Hillebrand H, Gruner D S, Borer E T, et al. 2007. Consumer versus resource control of producer diversity depends on ecosystem type and producer community structure. Proceedings of the National Academy of Sciences of the United States of America, 104(26): 10904-10909.

Hodgson J, Illius A W. 1996. The ecology and Management of Grazing Systems. Oxon: CAB International Wallingford.

Hooper D U, Chapin III F S, Ewel J J, et al. 2005. Effects of biodiversity on ecosystem functioning: a consensus of current knowledge. Ecological Monographs, 75(1): 3-35.

Hurlbert S H. 1984. Pseudoreplication and the design of ecological field experiments. Ecological Monographs, 54(2): 187-211.

Ives A R. 1995. Predicting the response of populations to environmental change. Ecology, 76(3): 926-941.

Ives A R, Gross K, Klug J L. 1999. Stability and variability in competitive communities. Science, 286 (5439): 542-544.

Ives A R, Carpenter S R. 2007. Stability and diversity of ecosystems. Science, 317(5834): 58-62.

Karsten H D, Fick G W. 1999. White clover growth patterns during the grazing season in a rotationally grazed dairy pasture in New York. Grass and Forage Science, 54(2): 174-183.

Kremen C. 2005. Managing ecosystem services: what do we need to know about their ecology?. Ecology Letters, 8(5): 468-479.

Lehman C L, Tilman D. 2000. Biodiversity, stability, and productivity in competitive communities. The American Naturalist, 156(5): 534-552.

Lepš J. 2004. Variability in population and community biomass in a grassland community affected by environmental productivity and diversity. Oikos, 107(1): 64-71.

Likens G E. 1985. An experimental approach for the study of ecosystems: the fifth Tansley lecture. Journal of Ecology, 73(2): 381-396.

Loreau M, Naeem S, Inchausti P, et al. 2001. Biodiversity and ecosystem functioning: Current knowledge and future challenges. Science, 294(5543): 804-808.

Loreau M, de Mazancourt C. 2008. Species synchrony and its drivers: neutral and nonneutral community dynamics in fluctuating environments. The American Naturalist, 172(2): E48-E66.

Loreau M, de Mazancourt C. 2013. Biodiversity and ecosystem stability: a synthesis of underlying mechanisms. Ecology Letters, 16(Suppl.): 106-115.

Magurran A E. 1988. Ecological Diversity and Its Measurement. Princeton: Princeton University Press.

McCann K S. 2000. The diversity-stability debate. Nature, 405(6783): 228-233.

Millard S P. 1987. Environmental monitoring, statistics, and the law: room for improvement. The American Statistician, 41(4): 249-253.

Petchey O L, Casey T, Jiang L, et al. 2002. Species richness, environmental fluctuations, and temporal change in total community biomass. Oikos, 99(2): 231-240.

Polley H W, Wilsey B J, Derner J D. 2007. Dominant species constrain effects of species diversity on temporal variability in biomass production of tall grass prairie. Oikos, 116(12): 2044-2052.

Ranta E, Kaitala V, Fowler M S, et al. 2008. Detecting compensatory dynamics in competitive communities under environmental forcing. Oikos, 117(12): 1907-1911.

Romanuk T N, Vogt R J, Kolasa J. 2006. Nutrient enrichment weakens the stabilizing effect of species richness. Oikos, 114(2): 291-302.

Sasaki T, Lauenroth W K. 2011. Dominant species, rather than diversity, regulates temporal stability of plant communities. Oecologia, 166(3): 761-768.

Socher S A, Prati D, Boch S, et al. 2013. Interacting effects of fertilization, mowing and grazing on plant species diversity of 1500 grasslands in Germany differ between regions. Basic and Applied Ecology, 14(2): 126-136.

Stewart-Oaten A, Murdoch W W, Parker K R. 1986. Environmental impact assessment: "pseudoreplication" in time? Ecology, 67(4): 929-940.

Taylor L R. 1961. Aggregation, variance, and the mean. Nature, 189(4766): 732-735.

Tilman D, Downing J A. 1994. Biodiversity and stability in grasslands. Nature, 367(6461): 363-365.

Tilman D, Lehman C L, Bristow C E. 1998. Diversity-stability relationships: statistical inevitability or ecological consequence? The American Naturalist, 151(3): 277-282.

Tilman D. 1999. The ecological consequences of changes in biodiversity: a search for general principles. Ecology, 80(5): $1455-1474$.

Valone T J, Barber N A. 2008. An empirical evaluation of the insurance hypothesis in diversity-stability models. Ecology, 89(2): 
$522-531$.

Wahlman H, Milberg P. 2002. Management of semi-natural grassland vegetation: evaluation of a long-term experiment in southern Sweden. Annales Botanici Fennici, 39(2): 159-166.

Walker B H, Holling C S, Carpenter S R, et al. 2004. Resilience, adaptability and transformability in social-ecological systems. Ecology \& Society, 9(2): 5.

Wan H W, Bai Y F, Schönbach P, et al. 2009. Effects of grazing management system on plant community structure and functioning in a semiarid steppe: scaling from species to community. Plant and Soil, 340(1-2): 215-226.

White R, Murray S, Rohweder M. 2000. Pilot Analysis of Global Ecosystems: Grassland Ecosystems. Washington DC: International Food Policy Research Institute and World Resources Institute.

Yang H J, Li Y, Wu M Y, et al. 2011. Plant community responses to nitrogen addition and increased precipitation: the importance of water availability and species traits. Global Change Biology, 17(9): 2936-2944.

Yang H J, Jiang L, Li L H et al. 2012. Diversity-dependent stability under mowing and nutrient addition: evidence from a 7-year grassland experiment. Ecology Letters, 15(6): 619-626.

Zhao G S, Liu J Y, Kuang W H, et al. 2015. Disturbance impacts of land use change on biodiversity conservation priority areas across China: 1990-2010. Journal of Geographical Sciences, 25(5): 515-529. 